International Journal of Child, Youth and Family Studies (2015) 6(1): 93-110

\title{
COMPARING THE EXPERIENCES AND WITHDRAWAL CONSIDERATIONS OF TREATMENT AND REGULAR FOSTER CARE PARENTS: THE CANADIAN PERSPECTIVE
}

\author{
Jessica Smith, Susan Rodger, Jason Brown, Laurel Pickel, \\ Wendy den Dunnen, and Alan Leschied
}

\begin{abstract}
This study investigated differences in the experiences of Canadian foster parents providing regular and treatment foster care and their consideration to withdraw from their position. Survey responses from 852 foster parents were analyzed subsequent to separating the participants into two groups based on the primary type of care they provided (regular $N=454$; treatment $N=398$ ). Results revealed that treatment foster care parents considered withdrawing at a higher rate compared to regular foster care parents. Subsequent analysis revealed numerous differences between the two groups regarding foster parents' experiences in fostering and reasons to withdraw. The results are discussed in the context of increasing concern for a declining number of foster parents with the coincidental increase in the number of children who enter foster care with higher rates of trauma and mental health disorders requiring a treatment response.
\end{abstract}

Keywords: foster parents, retention, treatment foster care, regular foster care, child welfare

Acknowledgement: This study was made possible through funding provided by the Canadian Child Welfare League as part of their Every Child Matters program and the Social Science and Humanities Research Council.

\footnotetext{
Alan Leschied, Ph.D. (the corresponding author) is a Professor in the Faculty of Education, University of Western Ontario, 1137 Western Road, London, Ontario, Canada, N6G 1G7. Telephone: (519) 661-2111, extension 88628.

E-mail: leschied@uwo.ca
} 
International Journal of Child, Youth and Family Studies (2015) 6(1): 93-110

Jessica Smith is a graduate of the Master's Program in Counselling Psychology at the University of Western Ontario.

Susan Rodger, Ph.D. is an Associate Professor in the Faculty of Education at the University of Western Ontario and served as a co-investigator in the larger study on foster care in Canada.

Jason Brown, Ph.D. is a Professor in the Faculty of Education at the University of Western Ontario and served as a co-investigator in the larger study on foster care in Canada.

Laurel Pickle is a graduate of the Master's Program in Counselling Psychology at the University of Western Ontario and served as a research associate in the larger study on foster care in Canada.

Wendy den Dunnen is a Doctoral Candidate in Psychology at the University of Ottawa and served as a research associate in the larger study on foster care in Canada.

Alan Leschied, Ph.D. is a Professor in the Faculty of Education at the University of Western Ontario and was the principal investigator in the larger study on foster care in Canada.

The larger study on retention and recruitment of foster care in Canada was funded through the Child Welfare League of Canada.

Jessica Smith was funded through the Social Sciences and Humanities Research Council during the period she worked on this study. 
International Journal of Child, Youth and Family Studies (2015) 6(1): 93-110

Merely increasing the number of homes won't solve the capacity problem: the state needs enough of the right mix of placements. Children have different needs; placements have different strengths. If a placement isn't equipped to meet the needs of a particular child, it is far more likely that the placement will experience problems and request that the child be moved. (Roper, 2008, p. 1)

The need for foster parents, particularly for children and youth with serious mental health disorders, continues to increase; however, the availability of foster homes continues to decrease. This is especially true for those foster parents with special training in particular. This incongruence has led to considerable research in the area of foster parents' experiences that relate to retention and recruitment. The motivations of foster parents, their experiences, and challenges are increasingly relevant in aiding organizations, such as child welfare agencies, that are charged with the recruitment of people to care for children who present with varying degrees of trauma as a result of living in conditions that have compromised their safety.

\section{Motivation and Retention of Foster Parents}

Daniel (2011) provides the most recent study to report that the motivation to foster is wide-ranging but essentially includes: fulfilling a personal need to be needed; a love of children, particularly those who are vulnerable due to their experience living with neglect or violence; joy in watching children grow and helping them in life; an awareness of the shortage of foster homes; and, similar to most all of the previous research on foster parent motivation, Daniel cites the overwhelming desire of foster parents to contribute to society. Foster parents are often assumed to possess these qualities and characteristics prior to making an application and attending for pre-service foster parent training. With such lofty ambitions to care for vulnerable children/youth and sufficient motivation, what then precipitates a foster parent to withdraw their services?

Denby, Rindfleisch, and Bean (1999) developed a scale that examined foster parent retention in the context of satisfaction linked to the challenges of the work, a feeling of competency to handle the needs of the children in their care, and having no regrets about their investment in their foster child. Factors influencing the intent to continue to foster highlighted their overall satisfaction, relationship with the sponsoring agency and specific workers, and the nature of being part of the decision-making in regard to the care of their foster child as of particular relevance in assessing foster parent satisfaction.

Rodger, Cummings, and Leschied (2006) examined foster parents from Southwestern Ontario regarding their motivation, satisfaction, challenges, and intent to continue fostering. Noteworthy from the Rodger et al. study, is the fact that almost twothirds of the foster parents in their sample reported considering withdrawing from their fostering commitment. Based on the scale developed by Denby and colleagues (1999), five factors emerged from this data. These included the predictors of satisfaction and the intent to continue fostering related to the nature of the relationship with the child's 
International Journal of Child, Youth and Family Studies (2015) 6(1): 93-110

worker, interacting with the foster child's primary family, seeing children returned to a bad situation, and losing children they were fond of.

While the Denby et al. (1999) and Rodgers et al. (2006) studies drew on samples of current foster parents regarding why they would consider quitting, Rhodes, Orme, and Buehler (2001) examined differences between three groups of foster parents that included former foster parents. While differences were found between all groups, foster parents who were currently invested in their fostering at the time of the study and who intended to leave reported that their reasons for leaving tended to reflect: health problems; the need to return to full-time work; receiving inadequate financial reimbursement; lacking day/respite care; experiencing problems with the child's birth parents; anticipating the difficulty in seeing a foster child leave their home; and not having enough say in the child's future planning. Some of the items of concern noted by Rhodes et al. pointed to a shift in the concerns of foster parents. First, with dual income families becoming an increasing economic necessity, foster families more commonly reported financial reimbursement as the reason for considering leaving than in past research. Second was the reported need for additional training after licensure; foster parents reported feeling increasingly unprepared to effectively respond to the level and nature of the needs of children/youth when compared to foster parents who planned to continue.

Increasingly complex issues with the children in care. Contributing to foster parent considerations for leaving are the changes in the children themselves who are entering the fostering system. Trocme et al. (2010), in their most recent summary of the maltreatment data in Canada, reported on the increase in the 2008 report regarding children experiencing mental health and behavioural challenges relative to their prior reports. Harman, Childs, and Kelleher (2000) reported in the United States that children in foster care were three to 10 times more likely to receive a mental health diagnosis than children not in foster care. Kools and Kennedy (2003) found considerable evidence to support the belief regarding increasing challenges in the physical and mental health status of children in foster care. These increasing needs reflected physical health concerns due to neglect and maltreatment, along with children not receiving proper mental health care once entering the foster care system (Kools \& Kennedy, 2003). Hebert and MacDonald (2009) suggested the same issues arose with Canadian foster children, complicated further by the effects of frequent transitioning between homes, a general lack of available medical information, misplaced records, and an absence of available social and educational services.

Additionally, Farris-Manning and Zandstra (2003) found that children in care display more behavioural problems with higher rates of special needs than in the past. This is relevant since a common challenge and reason for considering leaving fostering is the lack of in-service training. Specific areas where training is lacking pertains specifically to fostering adolescents, responding to the needs of sexually abused children, addressing the needs of children from different cultures (Rhodes et al., 2001), as well as the specific needs of children with behavioural difficulties (Denby et al., 1999). 
International Journal of Child, Youth and Family Studies (2015) 6(1): 93-110

\section{Types of Foster Care}

Of particular interest to the current study is the type of care commonly referred to as treatment, specialized, or therapeutic foster care. For purposes of simplicity, these various types of care are referred to as treatment foster care, unless otherwise specified by the authors in the reviewed literature. Treatment foster care involves caring for children who present with needs that are, by virtue of their nature or degree, unique, and require services beyond usual care. Parents are expected to help provide treatment for the children and receive additional training as a result (Wells \& D’Angelo, 1994). Children can have physical, medical, and mental health issues requiring special care from these foster parents. By having these types of programs, children can obtain the treatment they need while remaining within a family home environment (Reddy \& Pfeiffer, 1997).

Children and youth with serious mental health disorders are appearing in greater numbers in the child welfare system, an escalation first documented by Clausen, Landsverk, Ganger, Chadwick, and Litrowalk (1998) who noted an estimated two and a half times the rate of behavioural and emotional problems for children in foster care relative to a community-based sample of similar-aged children. Sullivan and van Zyl's (2008) refinement of this recognition noted that the rate of mental health disorder occurs as a function of age, with children/youth from ages 5 through 12 years showing the highest percentage of identified emotional need.

There are numerous reasons why this rate is as high as it is within the child welfare system. The reduced emphasis on residential treatment in the child and youth mental health system has meant that more children with moderate and higher rates of mental health disorders remain in the community, either within their families of origin or in alternate family arrangements such as foster care (Sunseri, 2008). There is also the move towards more integration within the systems of care with other community services, such as between child welfare and child and youth mental health (Horwath \& Morrison, 2007; Bai, Wells, \& Hillemeier, 2009). This fact has in turn shifted the roles of foster care providers in not only being viewed as part of the front line mental health service delivery system, but also mandated them as moving from what Villagrana (2010) characterizes as a shift from "caregiver to gatekeeper” of the broader mental health system.

Examining the fit between child need and foster care provider. Cox, Orme, and Rhodes (2003) brought a refinement in examining the "fit" between the needs of children and the backgrounds of foster parents in identifying the different factors influencing the willingness of certain foster parents to care for difficult children. They concluded that the issues in relation to the nature and complexity of the needs of the children in care should be considered when targeting the recruitment of foster parents. However, a frequently overlooked consideration in foster care recruitment and retention research and practice relates to the inclusion of an appreciation of the experiences of foster parents who provide particular types of homes such as regular, kinship, treatment, specialized, therapeutic, and emergency care. 
International Journal of Child, Youth and Family Studies (2015) 6(1): 93-110

Providing treatment foster care presents unique challenges in the relationships of foster parents with caseworkers, biological parents, and the children. Since these specialized foster parents are providing treatment as well as general care, other practitioners and / or community service agencies may be unsure of the nature of their relationship with these specially trained parents (Wells \& D’Angelo, 1994). The demands on treatment foster parents reflect the nature and complexity of the needs of the children they are asked to care for. Dorsey and colleagues (2012) recently documented the high rates of trauma exposure in children and youth who reside within treatment foster care placements, concluding that much of the emotional and behavioural difficulties with which these young people present is an extension of such early trauma.

While all foster parents extend themselves to care for children who have experienced some form of maltreatment within a structured and nurturing family environment, treatment foster parents will also be responsible for the provision of and support for intensive mental health services. Specialized foster parents are also more likely to report they are receiving inadequate support. Some parents report resentment toward caseworkers who appear not as committed to the care of the child as they are. Problems also arise when caseworkers are not supportive, do not provide information or resources to assist the parents, and do not provide respite care or relevant training and consultation (Chipungu \& Bent-Goodly, 2004).

\section{The Present Study}

The increased demand for fostering in combination with an increasing appreciation for the escalating behavioural and mental health concerns of children who enter foster care adds to the crisis of providing high quality services for these vulnerable children. This descriptive field study examined the experiences of foster parents who selfidentified as providing primarily either treatment foster care or regular foster care across Canada as they relate to retention and recruitment. The formal distinction of a treatment versus regular foster caregiver will vary across each province or territory, as this identification will formally reflect policies that relate to specific child welfare jurisdictions. Depending on the self-identification of the foster caregiver for this characterization provides the one consistent basis of distinguishing those foster parents who have been designated within their own agency, province or territory as a treatment caregiver.

\section{Method}

\section{Participants}

This research was part of a larger descriptive field study of Canadian foster parents completed by our research team in collaboration with the Child Welfare League of Canada (CWLC). This collaboration consisted of our research team working with CWLC researchers who approved the overall framework of reaching out to foster parents throughout Canada with the questionnaire that was designed by the researchers. Data 
International Journal of Child, Youth and Family Studies (2015) 6(1): 93-110

collection for this and the larger study was part of the CWLC initiative that has been functioning under the program title Every Child Matters, which, as stated on the CWLC website has been "a three year project dedicated to improving foster parent recruitment, retention and training practices by collecting and disseminating information, tools and best practices from around Canada” (Child Welfare League of Canada, 2014).

Recruitment Procedure. Every provincial and territorial foster parent association was contacted through CWLC advising them of the study. In turn, each of the provincial bodies contacted each child welfare agency regarding the study. Potential participants were invited to respond to a questionnaire, either a paper copy or electronically, regarding their fostering experience. Hence, recruitment of the foster parents in maximizing the response rate was facilitated through the CWLC by capitalizing on their links with provincial and territorial foster care associations. In addition, the CWLC's website contained an information page and link to the survey for consenting participants to access. All submissions by the participants were anonymous.

Contact with the provinces and territories generated a total of 941 completed surveys that were returned to the research team. Since there are no complete centralized provincial or territorial data sources regarding the actual number of foster parents within each jurisdiction, it is not possible to estimate the actual percentage rate of return that the sample size represents. As with other large-scale foster parent studies, the limitation of the current study reflects an absence of appreciation regarding the actual total number of foster parents who could potentially have been involved in the study. Canada's fostering system is comprised of ten provincial and three territorial jurisdictions that separately regulate foster care. Within each provincial and territorial jurisdiction, regional services such as child welfare agencies are charged with recruiting and supervising the foster parents for their own area. In the end, there is no formal mechanism to aggregate the total number of foster care providers across Canada.

Participants were separated into two groups based on the inclusion criteria of selfidentifying as providing primarily regular foster care (RFC) or treatment foster care (TFC). For inclusion in the RFC group, participants must have indicated in their responses that they provided one of the following types of care: (a) regular foster care only, or (b) regular foster care and another type of care (including emergency, kinship, relief care, etc., and excluding special or treatment foster care). Inclusion in the TFC group required participants to have indicated that they provided one of the following types of care: (a) treatment foster care only, (b) special foster care only, (c) treatment foster care and any other type of care (including regular foster care), or (d) special foster care and any other type of care (including regular foster care). The total number of participants who identified as meeting the inclusion criteria, as noted above, was 852 (89\% of the original sample). Of these participants, 454 were included in the RFC group (53\%) and 398 were included in the TFC group (47\%).

Survey Instrument. The survey instrument used in this study was developed by our research team based on the current literature regarding the retention and recruitment literature related to fostering and the common experiences and challenges faced by foster 
International Journal of Child, Youth and Family Studies (2015) 6(1): 93-110

parents. It was drawn largely from questionnaires used in previous research by Denby et al., (1999) and Rodger et al. (2006) with those items that had previously shown the ability to characterize the relevant issues in regard to recruitment and retention.

The survey asked a variety of questions related to information on foster parents and their experiences. The first section asked participants about their foster home and history of foster care, including the type of care provided, details regarding which children are approved to be in their home (age/gender), and details regarding the children they have fostered (number of children, age/sex, length of stay). The second section asked for demographic information of the foster parent(s), including sex, age, race, marital status, and highest education level achieved. The third section asked questions related to the foster parent(s)' biological family, including how many biological/adopted children are in the home, the age range of their children, and source of income. The survey also asked questions regarding the motivation to become a foster parent (4-point Likert scale ranging from "not at all” to "a great deal”), and if the foster parent had considered withdrawing from fostering at any time (yes or no) and the reasons for this consideration (4-point Likert scale ranging from "not at all” to "a great deal"). The last section involved questions related to the parents' experiences of fostering, with responses on a 7-point Likert scale from “completely disagree” to “completely agree”.

Demographics. The demographic information reflected the primary parent within the family who completed the survey. For both regular foster care (RFC) and treatment foster care (TFC) parents, $90 \%$ of the sample was female. The average age of TFC parents was higher $(M=58.30, S D=10.51)$ than RFC parents $(M=52.13, S D=9.61$; $t(836)=-5.53, p<.001)$. No racial differences were found between groups, with $75 \%$ of RFC participants and 80\% of TFC participants identifying as Euro-Canadian (Caucasian). Just over one-third of the sample in both groups (38\% RFC, 34\% TFC) reported being married. A significant difference was found pertaining to marital status, $\chi^{2}(6, N=847)$ $=17.53, p<.01$. Post-hoc standardized residuals revealed that TFC parents reported being single less frequently than would be expected (std. residual $=-2.10$ ). With respect to education, over half (57\%) of the RFC parents and over two-thirds (68\%) of the TFC parents reported college/university as their highest level of education. The majority of families reported at least one parent working, if not both, and the foster parts in each group reported similar employment experience. TFC parents were more likely to report that fostering was their sole source of income along with retirement income $\left(\chi^{2}=8.11, \mathrm{p}\right.$ $<.01)$.

\section{Results}

\section{Foster Parents' Home and Family}

Differences with respect to home and family reflected that TFC parents had been fostering for longer $(t(778)=-8.74, p<.001)$, fostered more children overall $(t(548)=$ $-5.34, p<.001)$, were more likely to have fostered more children at one time $(t(846)=$ $-4.85, p<.001)$, and fostered children for longer periods of time $(t(774)=-6.83, p<$ 
International Journal of Child, Youth and Family Studies (2015) 6(1): 93-110

.001) than those providing regular care. TFC parents also had more of their own biological children residing in the home $(t(847)=-2.02, p<.001)$.

Chi-square analyses were used to analyze additional differences between the two groups with regard to their foster home composition and experiences. Differences were found regarding the age of children primarily cared for by foster parents, $\left(\chi^{2}(4, N=\right.$ $846)=13.66, p<.01$ ) with more TFC parents caring for children aged 13 and above (std. residual $=2.03)$. TFC parents also reported fostering, to a greater extent, children with special needs $\left(\chi^{2}(1, N=846)=88.68, p<.001\right)$ and children considered medically fragile compared to RFC parents, $\chi^{2}(1, N=619)=52.15, p<.001$. Standardized residuals were all greater than $+/-1.96$.

With regard to the ages of children placed in care, while both groups of parents cared for infants, toddlers, young children, and latency aged children, TFC parents reported fostering adolescents, $\chi^{2}(1, N=657)=25.25, p<.001$, and young adults, $\chi^{2}$ $(1, N=505)=10.21, p<.001$, to a greater extent. TFC parents also fostered more infants when compared to RFC parents $(t(198)=-2.33, p<.05)$.

While most children entering foster care have special needs or have experienced abuse, there are also other ways in which foster children are unique. TFC parents reported fostering more children with physical $\left(\chi^{2}(1, N=415)=7.74, p<.01\right)$ and behavioural $\left(\chi^{2}(1, N=647)=4.89, p<.05\right)$ special needs.

\section{Motivations to Foster}

Foster parents were asked to what extent certain conditions contributed to their decision to become foster parents. The conditions with the highest rating reflected that foster parents "wanted to take in children who needed loving parents" and "wanted to save children from further harm". TFC parents were more likely to endorse that they "wanted to increase household income" than RFC parents $(t(761)=-2.82, p<.001)$. RFC parents "wanted to adopt, but were unable to do so" more than TFC parents, ( $t$ (735) $=3.08, p<.001$ ), however this factor was amongst the least endorsed overall. The factor that was endorsed the least for both groups was "wanting to give care as a religious obligation”.

\section{Withdrawal Considerations}

Foster parents were asked if they had considered withdrawing from fostering at any one time. A chi-square test for independence was used to analyze differences in response to this question. A significant difference was found between the groups, $\left(\chi^{2}\right.$ $(1, N=843)=15.30, p<.001)$. Post-hoc analyses revealed standardized residuals greater than $+/-1.96$ in two cells. RFC parents reported they had not considered withdrawing more than expected (std. residual $=2.20$ ), and TFC parents reported withdrawing less than expected (std. residual $=-2.35$ ). 
International Journal of Child, Youth and Family Studies (2015) 6(1): 93-110

Of those foster parents who had considered withdrawing from their role, the extent to which different situations influenced their decision was considered. Responses ranged from 0 (not at all) to 3 (a great deal). Of the potential situations influencing withdrawal, the highest-rated reason by the RFC parents was "seeing children sent back to a bad situation" $(M=1.38, S D=1.25)$. This was also rated high for the TFC parents $(M=1.42, S D=1.21)$, however the highest-rated reason for the TFC parents was "agency red tape" $(M=1.55, S D=1.22)$. TFC parents also endorsed this reason significantly more than RFC parents, $(t(518)=-1.99, p<.05)$. Other differences included "foster care boarding rates insufficient" $(t(518)=-2.92, p<.001)$, "significant personal loss of a family member(s)" $(t(434)=-2.86, p<.001)$ and "lack of support services such as respite care” ( $t$ (513), $=-2.37 p<.001)$, which TFC parents endorsed as reasons for considering withdrawal more than RFC parents. Foster parents also had the opportunity to list other reasons for their consideration to withdraw and these reasons seemed to contribute the most for those parents who listed them ( $M=1.86 \mathrm{RFC}, M=$ 1.92 TFC). Some reasons listed included age, retirement, burnout/fatigue, issues with the agency, and a lack of support or understanding from workers and agency.

\section{Foster Parent Experiences}

Foster parents were asked to rate, on a scale from completely disagree (1) to completely agree (7), various experiences they have had while fostering. Items were compiled into five categories based on previous research (Rodger et al., 2006) with the following results:

Perceptions of the agency/workers. The experience both groups of parents agreed with the most was not hesitating to call their agency or worker when they had concerns; however RFC parents agreed with this more than TFC parents, $(t(716)=2.17, p<.05)$. Parents providing RFC also agreed more with the statement "agency workers share fully about the background and problems of children whom they ask my family to accept", $(t(811)=2.22, p<.05)$.

Challenging aspects of fostering. Numerous differences were found between the groups within the category related to the challenges of fostering. TFC parents identified that boarding rates were insufficient $(t(817)=-2.87, p<.001)$, and that reimbursements for clothing, spending, etc., were insufficient as well $(t(810)=-2.39, p<.05)$ compared to RFC parents. TFC parents also reported more challenges with agency red tape interfering with their ability to foster $(t(813)=-2.13, p<.05)$. Parents providing RFC had more challenges with training requirements being met $(M=5.47, S D=1.81)$ than TFC parents $(M=5.98, S D=1.48), t(818)=-4.42, p<.001$. Additionally, RFC parents did not feel as respected when their family experienced a significant personal loss as TFC parents $(t(732)=-2.11, p<.05)$.

Confidence, satisfaction, and training. Both groups agreed with all of the statements in this category reported in the need for more training and overall levels of satisfaction. No significant differences were found between the groups with regard to this category. 
International Journal of Child, Youth and Family Studies (2015) 6(1): 93-110

Community and the child welfare system. More parents disagreed with these statements than any other category, as the lowest mean was 3.66. Overall, few differences were found between the groups. More RFC parents agreed that the child welfare systems responded appropriately to the needs of children throughout their lifespan than did TFC parents $(t(779)=4.59, p<.001)$. Parents providing RFC were also more satisfied with the child welfare system's ability to assess risk of children in a way that does not penalize biological parents/families for circumstances beyond their control, such as poverty $(\mathrm{t}(741)=2.19, p<.05)$.

Overall. Categorical differences existed reflecting the challenging aspects of foster care $(t(769)=-3.70, p<.001)$ and perceptions of the foster care system and community $(t(816)=2.05, p<.05)$. The category with the highest mean for both groups reflected confidence and satisfaction ( $M=6.31 \mathrm{RFC}, M=6.26 \mathrm{TFC})$ with no differences, indicating that parents in both groups feel equally confident and satisfied. When combining all means per group, there was no significant difference found, indicating that holistically, parents providing either type of care have similar experiences. However, individual differences exist and were revealed when analyzing the responses separately as described above.

\section{Summary}

TFC parents provided foster care for more years, to more children overall and at one time, and for longer periods of time. They also had more children leave their home in the past year. In addition, TFC parents had fostered, to a greater degree, children from other cultures, older children, those with special needs, especially medical and behavioural special needs, and children who had experienced all types of abuse. Some differences existed in terms of the motivation to become a foster parent, with TFC parents identifying financial gain as a motivating factor more than RFC parents. Although TFC parents endorsed, as a strong motivating factor, wanting to save children from further harm, RFC parents also identified this factor to a greater extent, as well as fostering as an adoption alternative. In addition to these differences, TFC parents considered withdrawing their services more than expected when compared to RFC parents. The reasons foster parents identified for considering withdrawal differed as well, with TFC parents identifying insufficient rates, issues with agency red tape, and a lack of support from workers to a greater degree. With regard to the foster parenting experience, overall differences were found with regard to challenging aspects of foster care and community/agency perceptions, with TFC parents facing more challenges and having more negative perceptions of the community and agency's role in adequately caring for children.

\section{Discussion}

Eight hundred and fifty-two Canadian foster parents completed a questionnaire related to demographic characteristics, aspects of and experiences with fostering, consideration of withdrawal from their role, and the reasons prompting withdrawal. Data were analyzed in an effort to examine potential differences in the views of foster parents 
International Journal of Child, Youth and Family Studies (2015) 6(1): 93-110

who provide treatment-oriented care relative to non-treatment, regular foster care parents. Key findings included TFC parents having more experience as foster parents, fostering more children at one time, and fostering children for longer periods of time than the RFC parents. These TFC parents also fostered children who were older and were more inclined to be fostering children with physical and behavioural challenges. While the initial motivations to foster were similar, differences were found between the groups in relation to their consideration of withdrawing from their position. TFC parents endorsed consideration to withdraw to a greater degree. Reasons more common among TFC parents related to a lack of sufficient funds, agency red tape, and lack of support from workers.

\section{Relevance to Previous Research}

Motivations to foster. Previous research has shown that foster parents' motivation to foster children is related to internal variables, most prominently the love of children and altruistic values to help those in need (Daniel, 2011; Denby et al., 1999; MacGregor, Rodger, Cummings, \& Leschied, 2006). Consistent with previous research, participants in this study rated "wanted to take in children who needed loving parents" and "to save children from further harm" as characterizing the most influential reasons to foster. Of importance, in most cases becoming a treatment foster parent requires first providing regular foster care for a considerable length of time. Thus, motivations to foster initially relate to becoming a regular foster parent. A difference was found with the current sample of TFC parents endorsing monetary gain as an external motivating factor, although it was rated lower than internal variables, which is consistent with previous research (Daniel, 2011; Kirton, 2001). More TFC compared to RFC parents had a gross income of under $\$ 20,000$. Additionally, more TFC parents indicated fostering as their sole source of income. While initially a foster parent does not provide treatment care, their lower income could be a motivating factor to begin fostering and later transition into providing treatment care, as the monetary gain is higher.

Experiences fostering. Due to the years of experience required to become a treatment foster parent, as expected, participants in the TFC group had fostered for more years and provided care to more children. As predicted, due to the nature of the work, TFC parents fostered more children with special needs and who had experienced multiple forms of abuse. As previous research outlined, more children are entering care who have experienced a combination of neglect and abuse with multiple special mental health and behavioural needs (Kools \& Kennedy, 2003; Farris-Manning \& Zandstra, 2003). Clearly, there is a higher demand for parents providing TFC. As would be expected given the mandate of TFC, it is these parents who are fostering the more challenging children.

Withdrawal considerations. TFC parents endorsed the consideration to withdraw from the foster parent role more frequently when compared to RFC parents. Although no past research has examined the differences between these two types of care, it is apparent that foster parents in general consider withdrawing from service at a very high rate. Denby and colleagues (1999) found that variables predictive of the intent to continue fostering included overall satisfaction and the readiness to call a social worker in times of 
International Journal of Child, Youth and Family Studies (2015) 6(1): 93-110

crisis. The current research found that TFC parents hesitated more when calling their worker for support, which according to Denby et al., would account partly for their withdrawal consideration. Rodger and colleagues (2006) found challenging aspects of care to be predictive of parents' withdrawal considerations. In the current study, TFC parents encountered more challenges than RFC parents, which would be predicative of their higher rates of consideration to withdraw. Although in the current study there were no differences in training experiences between the two groups, RFC parents endorsed the statement "my training requirements were met" less than the TFC parents. This could reflect the current increase in children with special needs being placed in RFC since the capacity within the TFC homes is already overextended and, as a result, children with exceptional needs are being placed in RFC as well.

A troubling finding in the current study is that TFC parents report not being fully informed about the children being placed in their care. Wells and D’Angelo (1994) found this to be prominent within their sample of specialized foster parents as well. By leaving out pertinent information, foster parents not only may be unable to provide the most effective care, but necessary trust between worker and parent may also be compromised. MacGregor and colleagues (2006) report that foster parents value this trust and maintaining it is reflected in higher rates of retention.

There were additional concerns expressed by TFC parents that are linked to retention. TFC parents reported a lack of support services from agencies that included respite care and insufficient financial reimbursement and boarding rates. Rhodes et al. (2001) found receiving inadequate financial reimbursement was linked to a withdrawal of service. Kirton (2001) also reported that parents providing care for more challenging children tended to view their financial compensation as low compared to when they fostered less compromised children. This finding is consistent with those reported by Rhodes and colleagues (2001) that point to a shift in the motivation to provide foster care that reflects the increasing demand for dual family incomes.

Although there were no differences between the groups with regard to personal satisfaction, there were differences in reported satisfaction with the community and child welfare systems. TFC parents were less satisfied and did not agree that the child welfare system responded appropriately to children's needs to the same degree as parents providing regular care. Denby and colleagues (1999) reported overall satisfaction to be predictive of the intent to continue fostering. While both groups in the current study rated levels of personal satisfaction and competence equally, TFC parents did have more challenges and dissatisfaction with the overall foster care system. The current study revealed differences between the groups with regard to one factor, the challenging aspects of care, which was the specific factor Rodger et al. (2006) found to be most predictive of the consideration to withdraw. The additional factor relating to satisfaction with the community and child welfare system was added to the survey in the current study, which was also an area of discontent for the TFC parents. Since the TFC parents scored lower on more factors of satisfaction, including the factor predictive of considering withdrawal, it is reasonable to assume that this could have contributed to the increase in withdrawal considerations for this group. 
International Journal of Child, Youth and Family Studies (2015) 6(1): 93-110

Despite the struggles, challenges, issues, and dissatisfactions, foster parents continue to provide care. When asked what motivated them to continue, parents responded that their love of the children was paramount. This finding echoed those of Kirton (2001) who noted that despite dissatisfaction with the financial aspects of fostering, parents reported it would not impact their ultimate decision to accept or refuse a placement, and that gaining additional funds would only assist them in providing more effective care. The intrinsic value of fostering due to a love of children, along with other altruistic factors, appears to outweigh the potential financial burden or discontent.

\section{Implications for Child Welfare Agencies}

This study investigated foster parents' motivations, satisfaction, and reasons to consider withdrawing from their role. This information is essential for child welfare agencies to better understand foster parents and the care that they provide to children.

The primary motivations to foster have remained stable over time and include the intrinsic motivators reflected in the love for children and wanting to care for those in need (Rodger et al., 2006; Denby et al., 1999; Daniel, 2001; MacGregor et al., 2006). What has shifted however, are the reasons for foster parents to consider a withdrawal of their services.

Retention. It will come as no surprise that those foster parents who are less satisfied in their role will consider withdrawing their services, and child welfare agencies need to be aware of those factors that impact satisfaction and how they can be addressed in order to improve the fostering experience. While both regular and treatment foster parents face more challenges and consider withdrawing from service to a greater degree than in the past, this is even truer for those parents providing treatment foster care. This reflects the increasing number of children presenting with more challenging behavioural and special needs (Kools \& Kennedy, 2003; Farris-Manning \& Zandstra, 2003), a lack of respite care, a lack of accurate and complete information being provided about the children being placed in care, challenges in the relationships between parents and agency workers, and underfunding for the services being provided by TFC parents. While these parents do receive higher rates of pay, it would appear that it remains insufficient to provide adequate care.

Training. Considerations for training improvements are common in the foster parent literature. However, when separating the parents by type of care in the current study, a difference in training experiences was revealed. Targeting the training strategies to those in need is crucial to improving the quality of care for children. Parents providing regular foster care reported their training requirements were met less often compared to the treatment parents. Although treatment foster care parents receive ongoing training due to the intensity of care they provide, child welfare agencies should not be overlooking the training needs of parents providing regular care. The positive impact of additional training in regard to retention has been evident for some time, as outlined by Price and his colleagues (2008). 
International Journal of Child, Youth and Family Studies (2015) 6(1): 93-110

\section{Considerations for Future Research}

While the current study is among the first to separate foster parents into distinct groups for analyses, the sample was restricted to current foster parents who have considered withdrawing from their role and does not include those who actually did leave. Future research should consider comparing a similar sample of former foster parents who have actually withdrawn. Second, there are various types of foster care available across Canada beyond the regular and treatment groups in the current study. Future research should investigate differences in the experiences of foster parents providing other types of foster care, such as emergency and kinship care, which would further help specify the information child welfare agencies could use to improve recruitment, retention, and training strategies, as well as the care for children. Third, there are numerous agencies and services that provide foster care for children in Canada. It is currently not possible to estimate the actual number of parents involved in fostering in the country, nor estimate - even within the current sample of parents - what the actual population parameters are. For example, while the current sample of 852 parents is large relative to sample sizes in other studies, it is not possible to estimate what percentage of the total number of foster parents this sample represents and hence will be a limiting factor in generalizing the current findings. Effort needs to be made to estimate the actual aggregate number of foster parents that currently provide service in Canada.

Lastly, while there is an awareness of the demand for a variety of foster care providers to meet the range of needs that vulnerable children and youth require, there remains a considerable gap in our knowledge regarding the impact of fostering. Turner and MacDonald's (2012) meta-analysis of treatment foster care programs concluded that there was evidence for TFC to be a promising program however, "the evidence is not robust and more research is needed to add to the limited number of studies in this area." (p. 501).

\section{Summary}

Notwithstanding the aforementioned limitations, the current study suggests that foster parents' experiences are not homogenous, and unique and important differences exist within the group of parents who provide different types of care. Parents providing treatment foster care foster more children, foster more children with difficult behavioural and special needs, encounter more challenges, and consider withdrawing from their position to a greater extent than foster parents providing regular care. These findings indicate that it would be advantageous for child welfare agencies to relate to foster parents differentially relative to the type of care they provide. No longer can assumptions be made that parents providing different types of care have similar experiences. Each group of foster parents has unique experiences that impact their intention to continue or withdraw from their fostering position. 
International Journal of Child, Youth and Family Studies (2015) 6(1): 93-110

\section{References}

Bai, Y., Wells, R., \& Hillemeier, M. (2009). Coordination between child welfare agencies and mental health service providers, children's services use and outcomes. Child Abuse and Neglect, 33(6), 372-381. http://dx.doi.org/10.1016/j.chiabu.2008.10.004

Child Welfare League of Canada (CWLC). (2014). Every child matters. Ottawa, ON: Author. Retrieved from http://www.cwlc.ca/ecm)

Chipungu, S. S., \& Bent-Goodley, T. B. (2004). Meeting the challenges of contemporary foster care. The Future of Children, 14(1), 74-93. http://dx.doi.org/10.2307/1602755

Clausen, J. M., Landsverk, J., Ganger, W., Chadwick, D., \& Litrowalk, A. (1998). Mental health problems of children in foster care. Journal of Child and Family Studies, 7(3), 283-296.

Cox, M. E., Orme, J. G., \& Rhodes, K. W. (2003).Willingness to foster children with emotional and behavioral problems. Journal of Social Service Research, 29(4), 23-51. http://dx.doi.org/10.1300/j079v29n04_02

Daniel, E. (2011). Gentle iron will: Foster parents’ perspectives. Children and Youth Services Review, 33(6), 910-917. http://dx.doi.org/10.1016/j.childyouth.2010.12.009

Denby, R. W., Rindfleisch, N., \& Bean, G. (1999). Predictors of foster parent's satisfaction and intent to continue to foster. Child Abuse \& Neglect, 23(3), 287303. http://dx.doi.org/10.1016/s0145-2134(98)00126-4

Dorsey, S., Burns, B. J., Southerland, D. G., Cox, J. R., Wagner, H. R. \& Farmer, E. M. Z. (2012). Prior trauma exposure for youth in treatment foster care. Journal of Child and Family Studies, 21(5), 816-824. http://dx.doi.org/10.1007/s10826-011-9542-4

Farris-Manning, C., \& Zandstra, M. (2003). Children in care in Canada. Ottawa, ON: Child Welfare League of Canada.

Harman, J. S., Childs, G. E., \& Kelleher, K. J. (2000). Mental health care utilization and expenditures by children in foster care. Archives of Pediatrics \& Adolescent Medicine, 154(11), 1114-1117. http://dx.doi.org/10.1001/archpedi.154.11.1114

Hebert, P. C., \& MacDonald, N. (2009). Health care for foster kids: Fix the system, save a child. Canadian Medical Association Journal, 181(8), E123-E124. http://dx.doi.org/10.1503/cmaj.091627

Horwath, J., \& Morrison, T. (2007). Collaboration, integration and change in children's services: Critical issues and key ingredients. Child Abuse and Neglect, 31(1), 5569. http://dx.doi.org/10.1016/j.chiabu.2006.01.007 
International Journal of Child, Youth and Family Studies (2015) 6(1): 93-110

Kirton, D. (2001). Love and money: Payment, motivation and the fostering task. Child and Family Social Work, 6(3), 199-208. http://dx.doi.org/10.1046/j.1365-2206.2001.00208.x

Kools, S., \& Kennedy, C. (2003). Foster child health and development: Implications for primary care. Pediatric Nursing, 29(1), 39-46.

MacGregor, T. E., Rodger, S., Cummings, A. L., \& Leschied, A. W. (2006). The needs of foster parents: A qualitative study of motivation, support, and retention.

Qualitative Social Work, 5(3), 351-368. http://dx.doi.org/10.1177/1473325006067365

Price, J. M., Chamberlain, P., Landsverk, J., Reid, J. B., Leve, L. D., \& Laurent, H. (2008). Effects of foster parent training intervention on placement changes of children in foster care. Child Maltreatment, 13(1), 64-75. http://dx.doi.org/10.1177/1077559507310612

Reddy, L. A., \& Pfeiffer, S. I. (1997). Effectiveness of treatment foster care with children and adolescents: A review of outcome studies. Journal of American Academy of Child and Adolescent Psychiatry, 36(5), 581-588. http://dx.doi.org/10.1097/00004583-199705000-00007

Rhodes, K. W., Orme, J. G., \& Buehler, C. (2001). A comparison of family foster parents who quit, consider quitting, and plan to continue fostering. Social Service Review, 75(1), 84-144. http://dx.doi.org/10.1086/591883

Rodger, S., Cummings, A., \& Leschied, A. W. (2006). Who is caring for our most vulnerable children? The motivation to foster in child welfare. Child Abuse \& Neglect, 30(10), 1129-1142. http://dx.doi.org/10.1016/j.chiabu.2006.04.005

Roper, T. (2008). Creating foster care capacity for abused and neglected children. Austin, TX: Center for Public Policy Priorities. .

Sullivan, D. J. \& van Zyl, M. A. (2008). The well-being of children in foster care: Exploring physical and mental health needs. Children and Youth Services Review, 30(7), 774-786. http://dx.doi.org/10.1016/j.childyouth.2007.12.005

Sunseri, P. A. (2008). Chidren referred to residential care: Reducing multiple placements, managing costs and improving treatment outcomes. Residential Treatment for Children and Youth, 22(3), 55-66. http://dx.doi.org/10.1300/j007v22n03_04

Trocmé, N., Fallon, B., MacLaurin, B., Sinha, V., Black, T., Fast, E., ... Holroyd, J. (2010). Canadian incidence study of reported child abuse and neglect -2008. Ottawa: Public Health Agency of Canada.

Turner, W., \& MacDonald, G. (2012). Treatment foster care for improving outcomes in children and young people: A systematic review. Research on Social Work Practice, 21(5), 501-527. http://dx.doi.org/10.1177/1049731511400434 
International Journal of Child, Youth and Family Studies (2015) 6(1): 93-110

Villagrana, M. (2010). Mental health services for children and youth in the child welfare system: A focus on caregivers as gatekeepers. Children and Youth Services Review, 32(5), 691-697. http://dx.doi.org/10.1016/j.childyouth.2010.01.005

Wells, K., \& D’Angelo, L. (1994). Specialized foster care: Voices from the field. Social Service Review, 68(1), 127-144. http://dx.doi.org/10.1086/604036 